Mal J Nutr 27(2): 259-270, 2021

\title{
Fulfilment of minimum acceptable diet (MAD), short birth length and family income level are associated with stunting in children aged 6-23 months in Central Jakarta
}

\author{
Madinar*, Ervida Andina \& Endang L. Achadi \\ Department of Nutrition, Faculty of Public Health, Universitas Indonesia, Depok, \\ Indonesia
}

\begin{abstract}
Introduction: Stunting is a condition characterised by retardation in the growth and development of children as a result of chronic inadequate nutritional intake and/or recurrent infectious diseases. This research aims to determine the factors related to stunting occurrence among children aged 6-23 months. Methods: This cross-sectional study was carried out in 2019. The sample was 231 children selected by multistage random sampling technique from 13 Posyandu (integrated healthcare centres) in six administrative villages located across three sub-districts of the Central Jakarta region. Results: The results showed that the prevalence of stunting was $26.0 \%$ and minimum acceptable diet (MAD) was only met by $31.6 \%$ of the children studied. Chi-square analysis revealed that short birth length $(O R=2.176$; 95\% CI: $1.155-4.098)$ and family income level $(O R=0.388$; 95\% CI: 0.201-0.749) were significantly associated with stunting. Logistic regression showed that fulfilment of MAD, short birth length $(O R=0.471 ; 95 \% \mathrm{CI}: 0.244-0.909)$, and family income $(O R=0.387 ; 95 \% \mathrm{CI}: 0.197-0.759)$ were significant factors for stunting among children 6-23 months in Central Jakarta in 2019, with fulfilment of MAD as a dominant factor $(O R=3.29$; 95\% CI: 1.171-9.241). Conclusion: More efforts need to be done to achieve the recommended MAD for all children aged between 6-23 months and to prevent short birth length. Large scale studies to explore the role of MAD in reducing stunting and qualitative studies to identify the constraints and promoting factors to better infant and young child feeding practices are imperative for programme improvement.
\end{abstract}

Keywords: stunting, fulfilment of minimum acceptable diet, children aged 6-23 months.

\section{INTRODUCTION}

Stunting is defined as impaired growth and development that children experience from poor nutrition, repeated infection, and inadequate psychosocial stimulation, which in many cases, happen in the $1^{\text {st }} 1000$ days of life and is characterised by height-for-age

\footnotetext{
*Corresponding author: Madinar, S.Gz

Department of Nutrition, Universitas Indonesia, Depok, Indonesia

E-mail: madinar199@gmail.com
}

Prof. Dr. Endang L. Achadi, MPH, Dr.PH.

Faculty of Public Health, Universitas Indonesia, Depok, Indonesia

E-mail: endang.achadi@gmail.com

doi: https: / / doi.org/10.31246/mjn-2020-0045 
$z$-score (HAZ) of $<-2$ standard deviations $(S D)$ (WHO, 2010). Stunting is a highrisk health problem associated with obstructed development of body organs, decreased child performance at school, increased mortality risk in children (UNICEF, 2013; Tiwari, Ausman \& Agho, 2014; Sarma et al., 2017), increased risk of non-communicable diseases, short body posture as adults, and reduction in quality of life in the future (Dewey, 2016; Black, 2013; Rahab et al., 2018). In 2007, 2010, 2013, and 2018 (Indonesian Ministry of Health, 2018), the prevalence of child stunting in Indonesia were $36.8 \%, 35.6 \%, 37.2 \%$, and $30.8 \%$, respectively. Daerah Khusus Ibukota (DKI) Jakarta Province has a stunting prevalence of $22.7 \%$ and Central Jakarta has the highest prevalence compared with other regions of Indonesia, at 29.2\% (Indonesian Ministry of Health, 2016; Indonesian Ministry of Health, 2018), which is considered as a moderate public health problem (WHO, 1995).

The causes of stunting are multifactorial and include immediate causes (inadequate dietary intake and infection); underlying causes (household food insecurity, inadequate care and feeding practices, unhealthy household environment, and inadequate health services), and basic causes (household characteristics, sociocultural, economic and political context). Feeding practices play an important role in stunting and can be assessed in relation to the fulfilment of minimum acceptable diet (MAD), minimum dietary diversity (MDD), and minimum meal frequency (MMF), which are three out of the eight core indicators for assessing infant and young child feeding practices (UNICEF, 2012). Minimum dietary diversity or MDD for both breastfed and non-breastfed children aged 6-23 months is defined as receiving four or more food groups out of the seven food groups (grains, roots and tubers; legumes and nuts; dairy products; flesh foods; eggs; vitamin A-rich fruits and vegetables; and other fruits and vegetables) (UNICEF, 2012). In this case, non-breastfed children are favoured as infant formula is included under the dairy food group, while breast milk is not counted. However, because MDD is a proxy indicator for mean micronutrient density adequacy of a diet, the exclusion of breast milk from the seven food groups is considered fine (UNICEF, WHO, FANTA III \& USAID, 2017). Minimum meal frequency is defined as the minimum frequency in provision of solid, semi-solid, or soft foods of two (for age 6-8 months) or three (for age 9-23 months) times for breastfed children, and four times (623 months) (including formula) for non-breastfed children (UNICEF, WHO, FANTA III \& USAID, 2017). Thus, it captures the caloric sufficiency of a child's diet. Minimum acceptable diet (MAD) is a summary indicator of 6-23 months children meeting both MDD and MMF. This study aimed to determine the factors related to the occurrence of stunting among children aged 6-23 months in Central Jakarta in 2019.

\section{MATERIALS AND METHODS}

The study was a descriptive crosssectional survey. This survey was conducted in three sub-districts which represented the urban areas in Central Jakarta, DKI Jakarta Province, Indonesia. It was carried out during April and May 2019. The samples of the population selected for this study were mothers and their children (6-23 months) residing in the study area. In its final analysis, this research used primary data from 231 children aged 6-23 months, based on sample inclusion criteria. Children with infections and allergies at the time of the study were excluded. The sample calculation in this study used a two-different-proportion 
hypothesis test with $80 \%$ power, $95 \% \mathrm{CI}$, and a design effect of 1.5.

A multistage procedure was adopted in selecting respondents for this study. The sampling involved a three-stage process in the study area, which was composed of eight sub-districts, each containing 5-6 administrative villages. In the first stage, three sub-districts were selected by balloting from the eight sub-districts. Next, from each of the three chosen sub-districts, two administrative villages were selected by random sampling, giving a total of six administrative villages selected. Finally, from each of the administrative villages, two or three Posyandu were selected by random sampling to provide the sample population needed for the study (13 Posyandu $=231$ children $)$. From each household, only one mother-child pair was selected for the study. Ethical clearance was obtained from the Ethics Committee of the Public Health Faculty of Universitas Indonesia (ID: 128/UN2. F10/PPM.00.02/2019). Consent was obtained in writing from each participant after the purpose of the study was explained to them. All identities of the participants were kept confidential.

Information were collected from respondents using a content-validated, interviewer-administered questionnaire. The present questionnaire was adopted from three valid questionnaires - the Indonesia Demographic and Health Surveys (IDHS), National Basic Health Surveys (Riskesdas), and National Growth Monitoring Surveys (PSG), respectively. We did not test the validity and reliability of our questionnaire, with assumption that these questions were already pretested. Data collection was assisted by enumerators who had been trained and met the specified criteria. Data were collected by measuring children's length and through interviews with respondents conducted by trained data collectors. Secondary data used in this study were geographical data and the number of children in each Posyandu.

The height measurement of each child was obtained and converted into height-for-age (HFA) as an indicator of nutritional status. This was then expressed as $z$-score based on the standard reference of measurements using the World Health Organization (WHO) Anthro software. Children were classified as stunted (HFA $<-2 \quad z$-score), severely stunted (HFA $<-2 \quad z$-score) or not stunted (HFA $\geq-2 z$-score). Maternal knowledge regarding children's health and nutrition was assessed, and their overall knowledge was classified as 'met' or 'not met'. Children's dietary feeding practices were measured through 24hour dietary recalls using the WHO Infants and Young Children Feeding (IYCF) guidelines. These guidelines were designed to measure the fulfilment of MDD when the child ate at least four or more varieties of foods from the seven food groups in a 24-hour time period; fulfilment of MMF when the child received complementary foods in the minimum recommended number of times in the past 24 hours; and MAD, which is a composite indicator of MDD and MMF. With that, meeting the WHO recommended MAD meant that currently breastfed children aged 6-23 months met both the MDD and the MMF based on what the child ate and drank in the past day and night (Khanal, Sauer \& Zhao, 2013). However, meeting the MAD was slightly different for nonbreastfed children. Dietary diversity was calculated by using six food groups (excluding dairy products) at least four times a day and combining milk-related products (formula milk, milk, or yoghurt) with at least two feedings a day.

The other independent variables used were initiation of breastfeeding, colostrum feeding, exclusive breastfeeding, history of infection, 
Table 1. Distribution of height-for-age (HAZ) in children aged $6-23$ months in Central Jakarta, $n=231$

\begin{tabular}{lc}
\hline Height-for-age $(H A Z)$ & $\%$ \\
\hline Severe stunting $(<-3 S D)$ & 8.7 \\
Moderate stunting $(-3 S D$ to $<-2 S D)$ & 17.3 \\
Not stunting $(\geq-2 S D)$ & 74.0 \\
\hline
\end{tabular}

immunisation status, vitamin A supplementation, low birth weight, short birth length, family characteristics including mother's education level, family income level, family size, and birth order. These information were collected using questionnaires. Chi-squared test was used for bivariate analysis and logistic regression test was used for multivariate analysis, using the Statistical Package for Social Sciences (SPSS) software with a statistical significance of $p<0.05$. Normality test with Kolmogorov-Smirnov test showed that data in this study were normally distributed with a $p$-value of $0.200(p>0.05)$.

\section{RESULTS}

Table 1 shows that the overall prevalence of stunting was $26.0 \% \quad(8.7 \%$ severe stunting and $17.3 \%$ moderate stunting). Boys had a higher prevalence of stunting $(26.6 \%)$ than girls (25.2\%). In addition, older children (aged 12-23 months) had a higher prevalence of stunting $(30.6 \%)$ than younger children (aged 6-11 months) (17.9\%). Table 2 shows the specific fulfilment of each indicator for child feeding practices used in this study. The proportion of children who fulfilled MDD was $>50 \%$, while $>70 \%$ fulfilled MMF. However, the proportion of children who fulfilled MAD was lower than both MDD and MMF (31.6\%). Along with the increasing age of children, MDD achievement increased as evidenced by the highest MDD achievement in children aged 18-23 months. MMD achievement was then categorised into two based on the status of breastfeeding, namely children who were still given breast milk and who were not given breast milk. In all age groups, the percentage of those achieving MDD were higher than those who did not achieve MDD, except for children who were not given breast milk (age group 6-11 months), whereby the percentage of those achieving and not achieving MDD were the same, that was $50 \%$, respectively. In this study, it was also shown that MDD achievement in children who were still given breast milk (48.7\%) was lower compared to children who were not given breast milk (72.2\%).

Table 3 shows the percentage of each dietary diversity score (number of types of food groups consumed by children). Among children who were still given breast milk, the highest value for dietary diversity score in the 6-11 months and 12-17 months age groups was 3 (34.4\% and $37.7 \%)$, while those in the 18-23 months age group was 4 (42.9\%). The values of dietary diversity score in children who were not given breast milk were $3(45 \%), 4$ and 5 $(34.8 \%)$, and $4(41.7 \%)$ in children aged 6-11 months, 12-17 months, and 1823 months, respectively. Table 3 also illustrated that the order of the most consumed food groups were foods from group 1 (grains, roots, and tubers) at $97.4 \%$, foods from group 6 (fruits and vegetables rich in vitamin A), foods from group 4 (meat), foods from group 3 (dairy products), foods from group 7 (fruits and other vegetables), foods from group 5 (eggs), and foods from group 2 (nuts and processed products). From Tables 3 and 4 , it was observed that 2 children $(0.4 \%)$ 
Table 2. Distribution of the fulfilment of MDD, MMF and MAD in children aged $6-23$ months in Central Jakarta

\begin{tabular}{|c|c|c|c|c|c|c|c|c|}
\hline & \multicolumn{6}{|c|}{ Age (months) } & \multicolumn{2}{|c|}{ Total } \\
\hline & \multicolumn{2}{|c|}{$6-11$} & \multicolumn{2}{|c|}{$12-17$} & \multicolumn{2}{|c|}{$18-23$} & \multirow{2}{*}{$n$} & \multirow{2}{*}{$\%$} \\
\hline & $n$ & $\%$ & $n$ & $\%$ & $n$ & $\%$ & & \\
\hline $\begin{array}{l}\text { Fulfilment of MDD } \\
\text { (breastfed and non- } \\
\text { breastfed) }\end{array}$ & 84 & & 76 & & 71 & & 231 & \\
\hline Not met & & 57.1 & & 40.8 & & 29.6 & & 43.3 \\
\hline Met & & 42.9 & & 59.2 & & 70.4 & & 56.7 \\
\hline $\begin{array}{l}\text { Fulfilment of } \\
\text { MDD in breastfed } \\
\text { children }\end{array}$ & 64 & & 53 & & 35 & & 152 & \\
\hline Not met & & 59.4 & & 50.9 & & 37.1 & & 51.3 \\
\hline Met & & 40.6 & & 49.1 & & 62.9 & & 48.7 \\
\hline $\begin{array}{l}\text { Fulfilment of MDD in } \\
\text { non breastfed children }\end{array}$ & 20 & & 23 & & 36 & & 79 & \\
\hline Not met & & 50.0 & & 17.4 & & 22.2 & & 27.8 \\
\hline Met & & 50.0 & & 82.6 & & 77.8 & & 72.2 \\
\hline Fulfilment of MMF & 64 & & 53 & & 35 & & 152 & \\
\hline Not met & & 25.0 & & 31.6 & & 28.2 & & 28.1 \\
\hline Met & & 75.0 & & 68.4 & & 71.8 & & 71.9 \\
\hline Fulfilment of MAD & 20 & & 23 & & 36 & & 79 & \\
\hline Not met & & 76.2 & & 65.8 & & 62.0 & & 68.4 \\
\hline Met & & 23.8 & & 34.2 & & 38.0 & & 31.6 \\
\hline
\end{tabular}

only consumed breast milk without complementary foods, meanwhile there were 150 children (64.9\%) who consumed breast milk accompanied by complementary foods, and 79 children $(34.3 \%)$ who did not consume breast milk, but consumed complementary foods that were mostly accompanied by consumption of formula milk. Less than $50 \%$ of children reportedly received initial breastfeeding, but at most received colostrum (88.7\%), while only one-third $(29.4 \%)$ were exclusively breastfed during the period of 0-6 months. Two-third of children had infection history (69.3\%), while $7.8 \%$ had low birth weight (LBW), and $26.4 \%$ had short birth length (SBL). More than $70 \%$ of children had been fully immunised for their age, and $>80 \%$ had received vitamin A supplementation. More than half of the children's mothers had a relatively high education level (59.7\%). The proportion of children with a family size of $\leq 4$ members was $62.3 \%$, while $64.1 \%$ were in the first or second birth order in their families. In addition, the proportion of mothers with correct knowledge on exclusive 
Table 3. Distribution of Dietary Diversity Score (DDS) and food groups consumed by children aged $6-23$ months in Central Jakarta

\begin{tabular}{|c|c|c|c|c|c|c|c|c|}
\hline & \multicolumn{6}{|c|}{ Age (months) } & \multicolumn{2}{|c|}{ Total } \\
\hline & \multicolumn{2}{|c|}{$6-11$} & \multicolumn{2}{|c|}{$12-17$} & \multicolumn{2}{|c|}{$18-23$} & \multirow[b]{2}{*}{$n$} & \multirow[b]{2}{*}{$\%$} \\
\hline & $n$ & $\%$ & $n$ & $\%$ & $n$ & $\%$ & & \\
\hline \multicolumn{9}{|l|}{$\begin{array}{l}\text { Number of food groups } \\
\text { consumed (DDS) }\end{array}$} \\
\hline In breastfed children & 64 & & 53 & & 35 & & 152 & \\
\hline 0 & & 3.1 & & 1.9 & & 0.0 & & 2.0 \\
\hline 1 & & 7.8 & & 3.8 & & 0.0 & & 4.6 \\
\hline 2 & & 14.1 & & 7.5 & & 14.3 & & 11.8 \\
\hline 3 & & 34.4 & & 37.7 & & 22.9 & & 32.9 \\
\hline 4 & & 25 & & 34 & & 42.9 & & 32.2 \\
\hline 5 & & 12.5 & & 7.5 & & 17.1 & & 11.8 \\
\hline 6 & & 3.1 & & 7.5 & & 2.9 & & 4.6 \\
\hline In non-breastfed children & 20 & & 23 & & 36 & & 79 & \\
\hline 1 & & 0.0 & & 0.0 & & 2.8 & & 1.3 \\
\hline 2 & & 5.0 & & 0.0 & & 5.6 & & 3.8 \\
\hline 3 & & 45.0 & & 17.4 & & 13.9 & & 22.8 \\
\hline 4 & & 30.0 & & 34.8 & & 41.7 & & 36.7 \\
\hline 5 & & 20.0 & & 34.8 & & 30.6 & & 29.1 \\
\hline 6 & & 0.0 & & 8.7 & & 5.6 & & 5.1 \\
\hline 7 & & 0.0 & & 4.3 & & 0.0 & & 1.3 \\
\hline Food groups consumed & & & & & & & 231 & \\
\hline Grains, roots, and tubers & & & & & & & & 97.4 \\
\hline $\begin{array}{l}\text { Nuts and their processed } \\
\text { products }\end{array}$ & & & & & & & & 17.7 \\
\hline $\begin{array}{l}\text { Dairy products (milk, } \\
\text { yoghurt, and cheese) }\end{array}$ & & & & & & & & 54.1 \\
\hline $\begin{array}{l}\text { Meat (various meats, fish, } \\
\text { poultry and offal) }\end{array}$ & & & & & & & & 63.6 \\
\hline Eggs & & & & & & & & 24.2 \\
\hline $\begin{array}{l}\text { Fruits and vegetables rich } \\
\text { in vitamin A }\end{array}$ & & & & & & & & 69.7 \\
\hline Other fruits and vegetables & & & & & & & & 38.5 \\
\hline
\end{tabular}


Table 4. Factors associated with stunting (severe and moderate) in children aged $6-23$ months in Central Jakarta

\begin{tabular}{|c|c|c|c|c|c|c|c|c|}
\hline \multirow{3}{*}{ Characteristics } & \multicolumn{4}{|c|}{ Nutritional status (HAZ) } & \multirow{2}{*}{\multicolumn{2}{|c|}{ Total }} & \multirow{3}{*}{$\begin{array}{c}\text { OR } \\
(95 \% \mathrm{CI})\end{array}$} & \multirow{3}{*}{$p$-value } \\
\hline & \multicolumn{2}{|c|}{ Stunting } & \multicolumn{2}{|c|}{ No stunting } & & & & \\
\hline & $n$ & $\%$ & $n$ & $\%$ & $n$ & $\%$ & & \\
\hline \multicolumn{9}{|l|}{ Fulfilment of MDD } \\
\hline Not met & 28 & 28.0 & 72 & 72.0 & 100 & 100 & \multirow{2}{*}{$\begin{array}{c}0.831 \\
(0.460-1.501)\end{array}$} & \multirow[t]{2}{*}{0.644} \\
\hline Met & 32 & 24.4 & 99 & 75.6 & 131 & 100 & & \\
\hline \multicolumn{9}{|l|}{ Fulfilment of MMF } \\
\hline Not met & 19 & 29.2 & 46 & 70.8 & 65 & 100 & \multirow{3}{*}{$\begin{array}{c}0.794 \\
(0.419-1.507)\end{array}$} & \multirow[t]{2}{*}{0.590} \\
\hline Met & 41 & 24.7 & 125 & 75.3 & 166 & 100 & & \\
\hline \multicolumn{8}{|l|}{ Fulfilment of MAD } & \\
\hline Not met & 38 & 24.1 & 120 & 75.9 & 158 & 100 & 1.362 & \multirow[t]{2}{*}{0.413} \\
\hline Met & 22 & 30.1 & 51 & 69.9 & 73 & 100 & $(0.734-2.530)$ & \\
\hline \multicolumn{9}{|l|}{ Breastfeeding initiation } \\
\hline No & 30 & 24.8 & 91 & 75.2 & 121 & 100 & 1.450 & \multirow[t]{2}{*}{0.419} \\
\hline Yes & 30 & 27.3 & 80 & 72.7 & 110 & 100 & $(0.691-3.042)$ & \\
\hline \multicolumn{9}{|l|}{ Colostrum feeding } \\
\hline No & 5 & 19.2 & 21 & 80.8 & 26 & 100 & 1.540 & \multirow[t]{2}{*}{0.552} \\
\hline Yes & 55 & 26.8 & 150 & 73.2 & 205 & 100 & $(0.554-4.284)$ & \\
\hline \multicolumn{9}{|l|}{ Exclusive breastfeeding } \\
\hline No & 40 & 24.5 & 123 & 75.5 & 163 & 100 & 1.281 & \multirow[t]{2}{*}{0.545} \\
\hline Yes & 20 & 29.4 & 48 & 70.6 & 68 & 100 & $(0.681-2.410)$ & \\
\hline History of in & & & & & & & & \\
\hline Yes & 16 & 22.5 & 55 & 77.5 & 71 & 100 & 1.304 & 0.528 \\
\hline No & 44 & 27.5 & 116 & 72.5 & 160 & 100 & $(0.677-2.513)$ & \\
\hline Birth & & & & & & & & \\
\hline weight & 7 & 38.9 & 11 & 61.1 & 18 & 100 & 1.921 & 0.260 \\
\hline Normal birth weight & 53 & 24.9 & 160 & 75.1 & 213 & 100 & $(0.709-5.208)$ & \\
\hline Birth length & & & & & & & & \\
\hline th length & 23 & 37.7 & 38 & 62.3 & 61 & 100 & 2.176 & $0.023^{*}$ \\
\hline Normal birth length & 37 & 21.8 & 133 & 78.2 & 170 & 100 & $(1.155-4.098)$ & \\
\hline Immu & & & & & & & & \\
\hline No & 16 & 28.6 & 40 & 71.4 & 56 & 100 & 0.840 & 0.738 \\
\hline Yes & 44 & 25.1 & 131 & 74.9 & 175 & 100 & $(0.428-1.646)$ & \\
\hline Vitam & & & & & & & & \\
\hline No & 10 & 26.3 & 28 & 73.7 & 38 & 100 & 0.979 & 1.000 \\
\hline Yes & 50 & 25.9 & 143 & 74.1 & 193 & 100 & $(0.444-2.158)$ & \\
\hline Mother's e & & & & & & & & \\
\hline Low & 28 & 30.1 & 65 & 69.9 & 93 & 100 & 0.701 & 0.306 \\
\hline High & 32 & 23.2 & 106 & 76.8 & 138 & 100 & $(0.387-1.269)$ & \\
\hline Family incom & & & & & & & & \\
\hline Low (< Rp3,940,973.96) & 45 & 32.8 & 92 & 67.2 & 137 & 100 & 0.388 & $0.006^{*}$ \\
\hline High (> Rp3,940,973.96) & 15 & 16.0 & 79 & 84.0 & 94 & 100 & $(0.201-0.749)$ & \\
\hline Family size & & & & & & & & \\
\hline Large (> $4 \mathrm{~m}$ & 22 & 25.3 & 65 & 74.7 & 87 & 100 & 1.059 & 0.976 \\
\hline Small $(\leq 4$ members $)$ & 38 & 26.4 & 106 & 73.6 & 144 & 100 & $(0.576-1.948)$ & \\
\hline Birth order & & & & & & & & \\
\hline Third or above & 22 & 26.5 & 61 & 73.5 & 83 & 100 & 0.958 & 1.000 \\
\hline First or second & 38 & 25.7 & 110 & 74.3 & 148 & 100 & $(0.520-1.765)$ & \\
\hline
\end{tabular}

${ }^{*} p$-value $<0.05$ indicates statistical significance 
Table 5. Multivariate analysis on the factors associated with stunting in children aged $6-23$ months in Central Jakarta

\begin{tabular}{lccc}
\hline Independent variables & -value & OR & $95 \%$ CI \\
\hline Fulfilment of MDD & 0.062 & 0.435 & $0.181-1.044$ \\
Fulfilment of MMF & 0.119 & 0.529 & $0.238-1.178$ \\
Fulfilment of MAD & $0.024^{*}$ & 3.290 & $1.171-9.241$ \\
Short birth length & $0.025^{*}$ & 0.471 & $0.244-0.909$ \\
Family income level & $0.006^{* *}$ & 0.387 & $0.197-0.759$ \\
\hline
\end{tabular}

${ }^{*} p$-value $<0.05$ indicates statistical significance

** $p$-value $<0.01$ indicates statistical significance

breastfeeding was $88.3 \%$ from the total population. Two-third of mothers had correct knowledge on the right timing for introducing complementary foods $(65.8 \%)$ and most of them introduced complementary foods based on the consistency of food - semi-solid and soft $(40.7 \%)$.

Bivariate analysis is presented in Table 4 and indicated that birth length and family income level were significantly associated with stunting in children aged 6-23 months, while other variables were not significantly associated with stunting. From this study, there were no significant association between birth length and family income level according to fulfilment of MDD, MMF and MAD. The logistic multivariate analysis was conducted through several stages: bivariate analysis to select candidate variables, multivariate modelling, and interpretation of the modelling results. The results of the bivariate selection showed that only SBL and family income level fulfilled as candidates for multivariate analysis; however, we also included the fulfilment of MAD, MDD, and MMF because these variables were important and substantial in this study. Multivariate analysis in Table 5 indicated that fulfilment of MAD (OR=3.29; 95\% CI: $1.171-9.241), \mathrm{SBL}(O R=0.471 ; 95 \%$ CI: 0.244-0.909), and family income $(O R=0.387 ; 95 \%$ CI: 0.197-0.759) were variables significantly associated with stunting, after controlling for other selected variables (fulfilment of MDD, fulfilment of MMF, SBL, and family income level). Based on this research, fulfilment of MAD was a dominant factor in stunting in children aged 6-23 months in Central Jakarta.

\section{DISCUSSION}

Stunting in children is caused by many factors. Non-optimal feeding practices is one of the highest risk that leads to retardation in the growth and development of children. MAD is a useful indicator to see the progress of quantity and quality of children's food intake (WHO, 2010). Low dietary diversity and meal frequency practices are determinants for health and growth in children $<2$ years of age. They increase the risk of under-nutrition, illness, and mortality in infants and young children (Beyene, Worku \& Wassie, 2015). Even with optimum breastfeeding, children will become stunted if they do not receive sufficient dietary diversity and frequency over 6 months of age (Issaka et al., 2014). The study conducted by Jemide et al. (2016) found that there is a relationship between fulfilment of MAD and stunting. Another study from Kakati and Baruah (2015) found that the risk of stunting is greater in children who did not meet the fulfilment of MAD compared to those who met the fulfilment of MAD. 
The prevalence of stunting in this population was high, with $26 \%$ of children aged 6-23 months affected, and this level of stunting in Central Jakarta is categorised as a moderate public health problem by WHO (1995). The prevalence of stunting was higher in children aged 12-23 months than in children aged 6-11 months, and this finding is similar to results from Rwanda (Nsereko, 2018). As children age, their growth curve deviates from the normal curve in line with the increase in their nutritional needs (Terati \& Susanto, 2018). Stunting in male children was more prevalent than in females, reflecting the lower likelihood for females than males to become stunted during infancy and childhood, as well as the higher survival rate of infant females than infant males (Boylan, 2017). Based on children's feeding practices, this study found that the fulfilment of MAD indicator was lower than for other indicators (MDD and $\mathrm{MMF}$ ), because the fulfilment of MAD is a combination of the fulfilment of the other indicators (that is, in order to meet MAD, children should meet both MDD and MMF). In this study, we found that the fulfilment of MDD was lower than $\mathrm{MMF}$, and so this result influenced the lower proportion of fulfilment of MAD.

This study also showed that MDD achievement in children who were still given breast milk was lower compared to children who were not given breast milk. This can happen because children who were still given breast milk considered breast milk to be the main source of their nutrition and breast milk was not included in the food group for the achievement of MDD; while children who were not given breast milk consumed more complementary foods than children who were still given breast milk to meet their energy and nutrient needs (Marriot, 2011). Therefore, MDD achievement in children who were still given breast milk versus those who were not given breast milk cannot be compared because breast milk was not counted in this indicator when used to determine the quality of complementary feeding practices. Besides that, it is known that children who are not given breast milk would achieve better MDD because they are routinely given formula milk or other milk products that are included as one of the food groups in MDD (WHO, 2010). Therefore, MDD achievement indicators are more suitable for use in children who are not given breast milk because children would then only rely on complementary foods to meet their nutritional needs (Arimond \& Ruel, 2004).

Short birth length (SBL) was found to be a significant variable associated with stunting, with 2.176 OR value (95\% CI: 1.155-4.098). This proves that in our sample, children with SBL had 2.176 times higher risk of stunting than those who did not. This finding is similar to other research that showed the importance of maternal pregnancy nutrition for children's nutritional status (Dewi, Dewi \& Murti, 2019). After conducting further analysis, it was found that $23 \%$ of children who had a history of SBL also had a history of LBW. In addition, it was proven from this study that there were $37.7 \%$ of children who had a history of SBL. Family income level is a protective factor against stunting. Given the 0.388 OR value found in this study, children with higher family income level will consume more nutritionally rich foods than those with lower family incomes (Beal et al., 2018), whose intake varies less in terms of quantity of various important nutrients for children's growth such as protein, minerals, and vitamins (Lestari et al., 2018). This is related to the high purchasing power of children with high family income (Nshimyiryo et al., 2019). 
Other variables had no significant relationships with stunting in this study in terms of fulfilment of MDD, MMF, and MAD because the 24-hour recall method used did not include specific portions of foods and this may have led to biased results. Breastfeeding initiation, colostrum feeding, and exclusive breastfeeding were found to have no significant relationships, probably because mothers thought that these could provide children's nutritional needs without knowing that other variables also played an important role in meeting children's nutritional needs. History of infection had no significant relationship with stunting, probably because we only asked about infection in the preceding month, which was not representative of a child's entire history of infection. Low birth weight, immunisation status, vitamin A supplementation, and family characteristics also had no significant relationships in this study, because there were other significant factors that affected stunting, such as children's feeding practices and children's history of infection (UNICEF, 2013).

Multivariate analysis results showed that fulfilment of MAD, SBL, and family income were significant factors for stunting among children 6-23 months, with fulfilment of MAD as a dominant factor. MAD is a summary indicator of 6-23 months of children meeting both MDD and MMF. Due to the multidimensional feeding of adequate complementary foods to children aged 6-23 months, it is very important to use a combination of indicators that can identify the extent to which adequate feeding practices are being met (Guirindola, 2018). The results of this study showed that children who did not meet MAD were 3.29 times more likely to be stunted. The fulfilment of MAD is therefore very important because it represents the effect of both food quantity and quality on children's linear growth (Nsereko, 2018). A cohort study conducted in Bangladesh found that the fulfilment of MAD was a predictor of linear growth in children aged 6-24 months (Owais et al., 2016). The limitation of this study was that if the feeding practices conveyed by respondents to the researcher were different from the actual feeding practices in children, then this would have affected the accuracy of the research data. MAD was obtained from the calculation results of more than one variable, of which its accuracy is based on the feeding practices reported by respondents.

\section{CONCLUSION}

Given that the fulfilment of MAD is the strongest factor affecting stunting, we therefore recommend that programmes aimed at improving mothers' knowledge and behaviour related to child feeding practices need to be strengthened through education to pregnant and lactating women, especially those from low-income families. The fact that the fulfilment is worse among younger children indicates that the transition to complementary feeding needs special and early efforts. Short birth length indicates problems of growth and development in the womb, and therefore we recommend that mothers should be in good health and nutritional status both before and during pregnancy. Large scale studies to explore the role of MAD in reducing stunting and qualitative studies to identify the constraints and promoting factors to better IYCF practices are imperative for programme improvement.

\section{Acknowledgement}

The authors received no specific grant from any funding agency in the public, commercial or notfor-profit sectors. 


\section{Authors' contributions}

M, principal investigator, conceptualised and designed the study, led the data collection in Central Jakarta, conducted the study, prepared the draft of the manuscript, and reviewed the manuscript; EA, conducted the study, advised on data analysis and interpretation, and reviewed the manuscript; EAL, conceptualised and designed the study, advised on data analysis and interpretation, assisted in drafting of the manuscript, reviewed the manuscript, and provided the final approval for publication.

\section{Conflict of interest}

None declared.

\section{References}

Arimond M \& Ruel MT (2004). Dietary diversity is associated with child nutritional status: evidence from 11 demographic and health surveys. J Nutr 134:2579-2585.

Beal T, Tumilowicz A, Sutrisna A, Izwardy D \& Neufeld LM (2018). A review of child stunting determinants in Indonesia. Matern Child Nutr 14:1-10.

Black RE, Victora CG, Walker SP, Bhutta ZA, Christian P, De Onis M \& Uauy R (2013). Maternal and child undernutrition and overweight in low-income and middle-income countries. The Lancet 382:427-451.

Beyene M, Worku AG \& Wassie MM (2015). Dietary diversity, meal frequency and associated factors among infant and young children in Northwest Ethiopia: a cross-sectional study. BMC Public Health 15:1007.

Boylan S, Mihrshahi S, Louie JC, Rangan A, Salleh HN, Ali HI, Paduka RD \& Gill T (2017). Prevalence and risk of moderate stunting among a sample of children aged 0-24 months in Brunei. Matern Child Health J 21:56-66.

Dewey KG (2016). Reducing stunting by improving maternal, infant and young child nutrition in regions such as South Asia: Evidence, challenges and opportunities. Matern Child Nutr 12:27-38.

Dewi AR, Dewi YL \& Murti B (2019). Life course factors associated with stunting in children aged 2-5 years: A path analysis. J Matern Child Health 4:48-57.

Guirindola MO, Maniego MLV, Silvestre CJ, Acuin CCS (2018). Determinants of meeting the minimum acceptable diet among Filipino children aged 6-23 months. Philipp J Sci 147:75-89.
Indonesian Ministry of Health (2016). Hasil Pemantauan Status Gizi (PSG). Direktorat Gizi Masyarakat, Direktorat Jenderal Kesehatan Masyarakat, Jakarta: Kemenkes RI. From http: / / www.kesmas.kemkes.go.id/assets / uploads / contents / others / Buku-Saku-HasilPSG-2016_842.pdf_[Retrieved November 23 2019].

Indonesian Ministry of Health (2018). Laporan Hasil Riset Kesehatan Dasar (Riskesdas) Nasional 2007. Jakarta: Badan Litbangkes, Depkes RI.

Issaka AI, Agho KE, Burns P, Page A \& Dibley MJ (2014). Determinants of inadequate complementary feeding practices among children aged 6-23 months in Ghana. Public Health Nutr 18:669-78.

Jemide JO, Ene-Obong HN, Edet EE \& Udoh EE (2016). Association of maternal nutrition knowledge and child feeding practices with nutritional status of children in Clabar South local government area, Cross River State, Nigeria. Int J Home Sci 2: 293-298.

Kakati R \& Baruah R (2015). complementary feeding practices and nutritional status amongst 7-12 months infants in rural areas of Kamrup District, Assam. Int $J$ Adv Res 3:715722 .

Khanal V, Sauer K \& Zhao Y (2013). Determinants of complementary feeding practices among Nepalese children aged 6-23 months: findings from demographic and health survey 2011. BMC Pediatr 13:1-13.

Lestari S, Fujiati II, Keumalasari D \& Daulay M (2018). The prevalence and risk factors of stunting among primary school children in North Sumatera, Indonesia. IOP Publishing 125: 1 .

Marriott BP, White A, Hadden L, Davies JC \& Wallingford JC (2011). World Health Organization (WHO) infant and young child feeding indicators: associations with growth measures in 14 low- income countries. Matern Child Nutr 8:354-370.

Nsereko E, Mukabutera A, Iyakaremye D, Umwungerimwiza YD, Mbarushimana V \& Nzayirambaho M (2018). Early feeding practices and stunting in Rwandan children: A cross-sectional study from the 2010 Rwanda demographic and health survey. Pan Afr Med J 9:1-6. 
Nshimyiryo A, Hedt-Gauthier B, Mutaganzwa C, Kirk CM, Beck K, Ndayisaba A \& El-Khatib Z (2019). Risk factors for stunting among children under five years: a cross-sectional population-based study in Rwanda using the 2015 Demographic and Health Survey. BMC Public Health 19:175.

Owais A, Schwartz B, Kleinbaum DG, Suchdev PS, Faruque ASG, Das SK, \& Stein AD (2016). Minimum acceptable diet at 9 months but not exclusive breastfeeding at 3 months or timely complementary feeding initiation is predictive of infant growth in rural Bangladesh. PLOS ONE 11(10):e0165128.

Rahab M, Samy M, Elshazly R, Abd L \& Haridy L (2018). Catch Up and control malnutrition in stunted children under the age of 5 years by using recent recipe of nutrition. EC Nutrition 13:193-199.

Sarma H, Khan JR, Asaduzzaman M, Uddin F, Tarannum S, Hasan MM \& Ahmed T (2017). Factors influencing the prevalence of stunting among children aged below five years in Bangladesh. Food Nutr Bull 38:291-301.

Terati HY \& Susanto E (2018). Effects of diet and breastfeeding duration on the stunting status of children under 5 years of age at maternal and child health centres of the Palembang Regional Office of Health. Pak J Nutr 17:51-56.

Tiwari R, Ausman LM \& Agho KE (2014). Determinants of stunting and severe stunting among under-fives: Evidence from the 2011 Nepal Demographic and Health Survey. BMC Pediatr 14:1-15.

UNICEF (2012). Infant and Young Child Feeding (pp. 1-172). New York: United Nations Children's Fund. From https://reliefweb. int/sites / reliefweb.int/files / resources / Programming\%20Guide_Infant $\% 20$ and $\% 20$ Young\%20Child\%20Feeding.pdf [Retrieved July 26 2021].
UNICEF (2013). Improving child nutrition: The achievable imperative for global progress (pp. 1-14). New York: United Nations Children's Fund. From https://data.unicef.org/ resources/improving-child-nutrition-theachievable-imperative-for-global-progress / [Retrieved November 23 2019].

UNICEF, WHO, UNICEF, WHO, FANTAI III \& USAID (2017). Meeting report on Reconsidering, Refining, Extending the World Infant and Young Chuld Feeding Indicators. New York: United Nations Children's Fund, World Health Organization, Food and Nutrition Technical Assistance III Project, U.S. Agency for International Development. From https:// data.unicef.org/resources / meeting-reportinfant-young-child-feeding-indicators / \# [Retrieved August 19 2020].

WHO (1995). Physical status: The use of and interpretation of anthropometry. Report of a WHO Expert Committee. World Health Organization. From https://apps.who.int/iris / handle/10665/37003 [Retrieved November 23 2019].

WHO (2010). Nutrition Landscape Information System (NLIS) country profile indicators: Interpretation guide. World Health Organization. From https://apps.who.int/iris / handle/10665/44397 [Retrieved November 23 2019]. 